\title{
MODELING OF KINETICS OF ISOTHERMAL IDIOMORPHIC FERRITE FORMATION IN A MEDIUM CARBON VANADIUM-TITANIUM MICROALLOYED STEEL
}

\author{
C. CAPDEVILA, F. G. CABALLERO, and C. GARCÍA DE ANDRÉS
}

\begin{abstract}
The present paper is concerned to the theoretical and experimental study of the growth kinetics of idiomorphic ferrite in a medium carbon vanadium-titanium microalloyed steel. A theoretical model is presented in this work to calculate the evolution of isothermal austenite-to-idiomorphic ferrite transformation with time for a given temperature. Moreover, the nature, size and distribution of the inclusions which are responsible of the intragranular nucleation of idiomorphic ferrite have been characterized by scanning electron microscopy. Finally, the influence of austenite grain size in the isothermal decomposition of austenite in idiomorphic ferrite has been

C. CAPDEVILA, Research Associate, F.G. CABALLERO, Research Associate, and C. GARCÍA DE ANDRÉS, Senior Research Fellow, are in the Department of Physical Metallurgy, Centro Nacional de Investigaciones Metalúrgicas (CENIM), Consejo Superior de Investigaciones Científicas (CSIC), Avda. Gregorio del Amo, 8, 28040 Madrid, Spain. C.CAPDEVILA currently is at the Department of Materials Science and Metallurgy, University of Cambridge, Pembroke Street, Cambridge CB2 3QZ, UK
\end{abstract}


thoroughly analyzed. An excellent agreement (higher than $90 \%$ in $\mathrm{R}^{2}$ ) has been obtained between experimental and predicted values of volume fraction of idiomorphic ferrite.

\section{INTRODUCTION}

Toughness and other mechanical properties of steels are critically affected by their microstructure. It is well known that proeutectoid ferrite can nucleate at inclusions within coarse austenite grains resulting in a very fine microstructure. Recently, this phenomenon has received great attention because of the need for toughness, especially when conventional austenite grain refinement techniques are not enough.

Idiomorphic and acicular ferrite are the microstructures that affect the strength and particularly the toughness of weld deposits ${ }^{[1-4]}$. There is a large amount of works on acicular ferrite formation ${ }^{[5-8]}$, but in contrast, idiomorphic ferrite formation has been rarely studied. Some studies reported that idiomorphs nucleate at precipitates of titanium oxide $\left(\mathrm{Ti}_{2} \mathrm{O}_{3}\right)$, manganese sulfide $(\mathrm{MnS})$, and vanadium nitride $(\mathrm{VN})^{[1,9-10]}$. Those studies also analyzed the reason for which such precipitates act as viable sites for intragranular ferrite nucleation. However, the nucleation and growth kinetics for idiomorphic ferrite formation were not investigated.

Although the kinetics of allotriomorphic ferrite ${ }^{[11-12]}$, pearlite ${ }^{[13-14]}$ and acicular ferrite formation are well established ${ }^{[15]}$, kinetic theory for idiomorphic ferrite formation has not been adequately developed yet. This work aims to study the isothermal decomposition of austenite into idiomorphic ferrite and analyze the influence of the prior austenite grain size (PAGS) on the nucleation and growth of idiomorphic ferrite. A mathematical model that describes the kinetics of idiomorphic ferrite formation during the isothermal decomposition of austenite is also proposed. 


\section{EXPERIMENTAL}

The chemical composition of the steel studied is presented in Table 1 . The material was supplied in the form of $50 \mathrm{~mm}$ square bars, obtained by conventional casting as a square ingot (2500 kg) and hot rolling to bar.

Table I. Chemical composition (wt - \%)

\begin{tabular}{ccccccccccc}
\hline $\mathrm{C}$ & $\mathrm{Si}$ & $\mathrm{Mn}$ & $\mathrm{Cr}$ & $\mathrm{Al}$ & $\mathrm{Ti}$ & $\mathrm{V}$ & $\mathrm{Cu}$ & $\mathrm{O}$ & $\mathrm{Mo}$ & $\mathrm{S}$ \\
\hline 0.37 & 0.56 & 1.45 & 0.04 & 0.024 & 0.015 & 0.11 & 0.14 & 0.004 & 0.025 & 0.043
\end{tabular}

The isothermal decomposition of austenite has been analyzed by means of a high-resolution

dilatometer DT 1000 Adamel-Lhomargy described elsewhere ${ }^{[16]}$. Cylindrical dilatometric samples of $2 \mathrm{~mm}$ in diameter and $12 \mathrm{~mm}$ in length, machined parallel to the rolling direction of the bar, were used for these tests. The change in length of the specimen is transmitted via amorphous silica push rod. This variation is measured by a linear variable differential transformer (LVDT) sensor in a gas-tight enclosure enabling testing under vacuum or an inert atmosphere with accuracy better than $0.1 \mu \mathrm{m}$. The dilatometric curve (relative change in length $\left(d L / L_{o}\right)$ vs. time $(t))$ is monitored with the help of a computer assisted electronic device. The dilatometer is equipped with a very low thermal inertia radiation furnace. The heat radiated by two tungsten filament lamps is focused on the specimen by means of a bi-elliptical reflector. The temperature is measured with a $0.1 \mathrm{~mm}$ diameter Chromel - Alumel (Type K) thermocouple welded to the specimen. Cooling is carried out by blowing a jet of helium gas directly onto the specimen surface. The helium flow-rate during cooling is controlled by a proportional servo valve. Heating 
and cooling devices of this dilatometer ensure an excellent efficiency in controlling the temperature and holding time of isothermal treatments, and fast cooling in quenching processes.

With the aim of studying the influence of PAGS on the isothermal austenite-to-idiomorphic ferrite transformation, specimens were austenitized at two different temperatures (1273 K and $1523 \mathrm{~K}$ ) for $1 \mathrm{~min}$. Subsequently, specimens were isothermally transformed at $913 \mathrm{~K}$ during different times, and quenched under helium gas flow at a cooling rate of $200 \mathrm{~K} / \mathrm{s}$. Specimens were ground and polished using standardized metallographic techniques, and subsequently etched with 2pct-Nital solution to reveal the ferrite microstructure by optical microscopy.

The PAGS measurements were made on micrographs. The average grain size was calculated by using a linear intercept technique involving at least 50 intercepts, permitting the count of the number of grains intercepted by the grid line. The effects of a moderately non-equiaxed structure may be eliminated by counting the intersections of lines in four or more orientations covering all the observation fields with an approximately equal weight ${ }^{[17]}$. Table II shows the average PAGS in microns corresponding to both austenitization conditions.

Table II. Prior austenite grain size

\begin{tabular}{cc}
\hline $\mathrm{T} \gamma, \mathrm{K}$ & $P A G S, \mu \mathrm{m}$ \\
\hline 1523 & 76 \\
1273 & 11 \\
\hline $\mathrm{T} \gamma=$ Austenitization temperature
\end{tabular}

Measurements of volume fraction of idiomorphic ferrite $\left(V_{I D I}\right)$ were performed statistically by a systematic manual point counting procedure ${ }^{[17]}$. A grid superimposed on recorded 
micrographs provides, after a suitable number of placements, an unbiased statistical estimation of the $V_{I D I}$.

Finally, the morphology and nature of the inclusions were determined by means of scanning electron microscopy (SEM). Specimens were sectionalized longitudinally and transversally to the rolling direction, polished in the usual way and finished on $0.5 \mu \mathrm{m}$ diamond paste. Samples were slightly etched in a 2 pct-Nital solution for SEM examination in a JEOL JXA 840 scanning electron microscope operating at $15 \mathrm{kV}$ with an energy disperse X-ray analysis unit. Quantitative information on the size distribution of inclusions was obtained by means of an IBAS OPTIMAS 2.0 automatic image analyzer. SEM images were digitized with a resolution of $512 \times 512$ pixel and 256 gray levels. After images enhancement processes, the size of the inclusions was determined through the measurement of the two perpendicular diameters in the transversal section $\left(d_{1}\right.$ and $\left.d_{2}\right)$, and the highest diameter in the longitudinal section $\left(d_{3}\right)$. For that propose, a $512 \times 512$ points grid was used along with magnifications as high as 3000 times to characterize inclusions with a diameter lower than $0.1 \mu \mathrm{m}$. Minimums of 500 particles were counted to obtain a reliable result.

\section{RESULTS AND DISCUSSION}

\section{A. Size distribution and nature of inclusions}

Figure 1 shows the morphology of the inclusions in samples sectionalized longitudinally and transversally to the rolling direction, and a schematic illustration of their ellipsoidal shape. Figure 2 shows the frequency of the inclusion diameters experimentally obtained in a transversal $\left(d_{1}\right.$ and $\left.d_{2}\right)$ and longitudinal $\left(d_{3}\right)$ section. From the histograms of this figure, the average values 
of $d_{1}, d_{2}$ and $d_{3}$ have been obtained (Table III). EDX spectrum in Fig. 3 shows that all these inclusions are $\mathrm{MnS}$.

Table III. Diameters of ellipsoidal inclusions

\begin{tabular}{c|c|c}
\hline \multicolumn{2}{c|}{ Transversal section } & Longitudinal section \\
\hline$d_{1}, \mu \mathrm{m}$ & $d_{2}, \mu \mathrm{m}$ & $d_{3}, \mu \mathrm{m}$ \\
\hline $1.78 \pm 0.30$ & $1.16 \pm 0.20$ & $9.56 \pm 2.30$ \\
\hline
\end{tabular}

Idiomorphic ferrite nucleates intragranularly in the inclusions distributed inside the austenite grains. Thus, the volume fraction of idiomorphic ferrite is related to the volume fraction of inclusions in the steel. Kluken and Grong ${ }^{[18]}$ proposed an equation to estimate the volume fraction of inclusions by converting the analytical oxygen and sulfur concentration in the steel into an equivalent inclusion volume fraction. Considering the solubility of sulfur in the steel equal to 0.003 wt-pct ${ }^{[19]}$, the following equation has been derived:

$$
V_{V} \approx 10^{-2}[5.0\{\% O\}+5.4(\{\% S\}-0.003)]
$$

where $V_{V}$ is the volume fraction of inclusions in the steel and $O$ and $S$ are the oxygen and sulfur concentration of the steel, respectively, in wt-pct. $V_{V}=2.34 \times 10^{-3}$ for the studied steel (See Table 1 for oxygen and sulfur composition).

B. Role of PAGS on idiomorphic ferrite formation 
Ferrite which grows by diffusional mechanisms can be classified into two main forms: allotriomorphic ferrite and idiomorphic ferrite ${ }^{[20-21]}$. Allotriomorphic ferrite nucleates at the prior austenite grain boundaries and tends to grow along the austenite boundaries at a rate faster than in the normal direction to the boundary plane (Fig. 4). By contrast, idiomorphic ferrite nucleates at the inclusions inside the austenite grains and can be identified in the microstructure by its equiaxed morphology (Fig. 4). Consequently, the balance between the number of intragranular nucleation sites and those at the austenite grain boundaries is a very important factor in the competitive process of allotriomorphic - idiomorphic ferrite formation.

It is well known that an increase in the PAGS leads to a reduction in the number of nucleation sites at the austenite grain boundaries. Therefore, an increase in the PAGS indirectly favors the intragranular nucleation of ferrite, and then the formation of idiomorphic ferrite is enhanced instead of allotriomorphic ferrite. Likewise, as the PAGS increases, the number of inclusions trapped inside the austenite grains increases, promoting the intragranular nucleation of ferrite.

Assuming that ferrite nucleates primarily on grain boundaries, Grong ${ }^{[22]}$ reported that the total number of grain boundary nucleation sites per unit volume, $N_{V}^{G B}$ is given as:

$$
N_{V}^{G B}=n_{a} S_{V}^{G B}
$$

where $n_{a}$ is the number of nucleation sites per unit grain boundary area and $S_{V}^{G B}$ is the grain boundary surface area per unit volume. The value of $n_{a}$ can be expressed as $K / \delta^{2}$ where $K$ is a constant and $\delta$ is the atomic spacing (reasonable value of $2.5 \times 10^{-10} \mathrm{~m}$ ) ${ }^{[23]}$. As a second 
approximation, it could be also assumed the austenite grains are spherical in shape. Then, $S_{V}^{G B}$ is given as:

$$
S_{V}^{G B}=\frac{\pi\left(d_{\gamma} / 2\right)^{2}}{\frac{4 \pi}{3}\left(d_{\gamma} / 2\right)^{3}}=\frac{6}{d_{\gamma}}
$$

where $d_{\gamma}$ is the mean austenite grain diameter. In this work, a similar expression for the intragranular nucleation sites is proposed. Bearing in mind that $n^{I N C}$ is the total number of inclusions inside the austenite grain, the total inclusion surface area per unit volume, $S_{V}^{I N C}$, could be expressed by:

$$
S_{V}^{I N C}=S_{V o}^{I N C} n^{I N C}
$$

where $S_{V_{0}}^{I N C}$ is the inclusion surface area per unit volume for a particular inclusion. In this sense, and considering that all the inclusions are ellipsoids with the same size (average values in Table III), $S_{V o}^{I N C}$ is written as:

$$
S_{V o}^{I N C}=6 / d_{3}
$$

Moreover, $n^{I N C}$ could be expressed as the volume fraction of inclusions in the steel $\left(V_{V}\right)$ modulated by the ratio between the austenite grain size and the inclusion size, 


$$
n^{I N C}=\frac{d_{\gamma}}{\left(d_{1}+d_{2}\right) / 2} V_{V}
$$

Therefore, $S_{V}^{I N C}$ can be calculated as follows:

$$
S_{V}^{I N C}=\frac{6}{d_{3}} \frac{d_{\gamma}}{\left(d_{1}+d_{2}\right) / 2} V_{V}=\frac{12 d_{\gamma}}{d_{3}\left(d_{1}+d_{2}\right)} V_{V}
$$

On the other hand, the intragranular nucleation sites per unit volume, $N_{V}^{I N C}$, could be expressed by:

$$
N_{V}^{I N C}=n_{i} S_{V}^{I N C}
$$

where $n_{i}$ is the number of nucleation sites per unit surface area of inclusion which can be expressed as $K^{*} / \delta^{2}$ where $K^{*}$ is a constant and $\delta$ is the atomic spacing $\left(\delta=2.5 \times 10^{-10} \mathrm{~m}\right)^{[23]}$. Combining Eqn. (2) and (8) could be concluded that $S_{V}^{I N C} / S_{V}^{G B}$ represents a ratio between the density of intragranular and grain boundary nucleation sites. Figure 5 shows the evolution of this ratio with PAGS. According to this figure, the intragranular nucleation of ferrite becomes more relevant as PAGS increases. For a PAGS of $76 \mu \mathrm{m}$, about the 85 pct of the total number of nucleation sites for ferrite are intragranular, whereas for a PAGS of $11 \mu \mathrm{m}$ less than 1 pct of all the nucleation sites contributes to the intragranular nucleation of ferrite.

The equilibrium (or maximum) volume fraction of idiomorphic ferrite $\left(V_{E Q}\right)$ formed during the isothermal decomposition of austenite at a given temperature was determined by a 
combination of dilatometric and metallographic analysis. When the dilatometric curve reaches the saturation, i.e. no further dilatation due to transformation is observed, the isothermal decomposition of austenite is completed, and this time represents approximately the minimum holding time needed to reach the equilibrium volume fraction of idiomorphic ferrite. Since dilatometric curves do not allow us to discriminate between allotriomorphic and idiomorphic ferrite formation, only the metallographic examination of the microstructure will enable to determine accurately $V_{E Q}$. Figure 6 shows the microstructures obtained after isothermal decomposition of austenite during an hour at $913 \mathrm{~K}$ for a PAGS of $11 \mu \mathrm{m}$ and $76 \mu \mathrm{m}$. The experimental $V_{E Q}$ values for idiomorphic ferrite obtained at that temperature (2 pct for a PAGS of $11 \mu \mathrm{m}$, and 8 pct for a PAGS of $76 \mu \mathrm{m}$ ) are consistent with the fact that, intragranular nucleation of ferrite becomes more favorable than grain boundary nucleation as PAGS increases.

\section{Transformation model}

Idiomorphic ferrite is considered to grow under a parabolic law with time, and the assumption of a semi-infinite extent austenite with constant boundary conditions is considered a sensible approach for the kinetics of the isothermal decomposition of austenite into idiomorphic ferrite. On the other hand, the consideration of paraequilibrium is a good assumption for the kinetics of this transformation. In that case, substitutional solute atoms do not partition and the adjoining phases have identical $\mathrm{X} / \mathrm{Fe}$ atom ratios, where $\mathrm{X}$ represents the substitutional solute elements. Then, the substitutional lattice is configurationally frozen, but interstitial solutes such as carbon are able to partition and attain equilibration of chemical potential in both phases ${ }^{\text {[11] }}$. The three-dimensional parabolic thickening constant $\left(\alpha_{3}\right)$ is given by ${ }^{[24]}$ : 


$$
\alpha_{3}=\left[\frac{2 D\left(\bar{x}-x^{\gamma \alpha}\right)}{x^{\alpha \gamma}-\bar{x}}\right]^{1 / 2}
$$

where $x^{\gamma \alpha}$ and $x^{\alpha \gamma}$ are the austenite and ferrite paraequilibrium carbon content at the interface, respectively, $\bar{x}$ is the average carbon content of the austenite, and $D$ is the average diffusivity of carbon in austenite.

Idiomorphic ferrite formation occurs as follows: idiomorphs nucleate on inclusions randomly distributed in an existing austenite phase at a constant nucleation rate per unit area $(I)$ and subsequently, grow isotropically to form spherical particles. In diffusion-controlled growth, the radius of a particle formed after an incubation period $(\tau)$ will vary with the square root of time (t) as follows:

$$
r=\alpha_{3}(t-\tau)^{1 / 2}
$$

where $\alpha_{3}$ is considered constant as long as the far-field concentration in the matrix does not change. Therefore, the volume of an idiomorph after a time $t$ is given by:

$$
v= \begin{cases}\frac{4 \pi}{3} \alpha_{3}^{3}(t-\tau)^{3 / 2} & ,(t>\tau) \\ 0, & (t \leq \tau)\end{cases}
$$

Moreover, the number of idiomorphs $(N)$ formed in a time $d \tau$ is: 


$$
N=I S_{V}^{I N C} V d \tau
$$

where $V$ is the volume of austenite before isothermal decomposition.

At the stages of transformation, when particles start to impinge, the above theory does not adequately describe the kinetics of idiomorphic ferrite formation. Avrami ${ }^{[25]}$ introduced the concept of an extended volume to describe the volume of the particles whose growth is not impeded by impingement between particles. Particles are allowed to overlap and grow through each other. New nucleus forming in regions already transformed to idiomorphic ferrite, dubbed phantom nuclei, are also included in the extended volume calculation. Thus, the contribution of all the particles nucleated in the interval between $\tau$ and $\tau+d \tau$ to the extended volume of idiomorphic ferrite $\left(V_{I D I}^{e}\right)$ can be expressed as:

$$
d V_{I D I}^{e}=v N=\frac{4 \pi}{3} \alpha_{3}^{3}(t-\tau)^{3 / 2} I S_{V}^{I N C} V d \tau
$$

However, the actual change in volume, $d V_{I D I}$, can be determined from the change in extended volume just including the probability that some transformation to idiomorphic ferrite has already occurred. Thus, the volume of idiomorphic ferrite formed $\left(V_{I D I}\right)$ could be written as:

$$
d V_{I D I}=\left(1-\frac{V_{I D I}}{V}\right) d V_{I D I}^{e}
$$

Separating variables and integrating the following expression can be obtained: 


$$
-\ln \left(1-\frac{V_{I D I}}{V}\right)=\frac{4 \pi}{3} \int_{0}^{t} I S_{V}^{I N C} \alpha_{3}^{3}(t-\tau)^{3 / 2} d \tau
$$

Finally, the volume fraction of idiomorphic ferrite, $\xi$, can be easily evaluated assuming that $I$ and $\alpha_{3}$ are constant with time, and $V_{E Q}$ is the maximum volume fraction of austenite that transforms to idiomorphic ferrite:

$$
\xi=\frac{V_{I D I}}{V}=V_{E Q}\left[1-\exp \left(-\frac{8 \pi}{15} I S_{V}^{I N C} \alpha_{3}^{3} t^{5 / 2}\right)\right]
$$

The nucleation rate $I$ has been calculated according to Lange et al. ${ }^{[26]}$ and Reed and Bhadeshia ${ }^{[27]}$, taking into account the chemical composition of the studied steel, and its values for a temperature of $913 \mathrm{~K}$ is $5.50 \times 10^{8} \mathrm{~m}^{-2} \mathrm{~s}^{-1}$. The paraequilibrium carbon concentrations at the interface $x^{\alpha \gamma}, \mathrm{x}^{\gamma \alpha}$ have been obtained using a calculated multicomponent phase diagram as reported by Shiflet et al. ${ }^{[28]}$ ); The average diffusivity of carbon in austenite $D$ has been calculated according to Bhadeshia ${ }^{[29]}$. Finally, $S_{V}^{I N C}$ has been calculated from Eqn. (3). All those values are listed in Table IV .

\begin{tabular}{|c|c|c|c|c|c|}
\hline \multicolumn{2}{|c|}{$S_{V}^{I N C}, \mathrm{~m}^{-1}$} & \multirow[t]{2}{*}{$D, \mathrm{~m}^{2} \mathrm{~s}^{-1}$} & \multirow[t]{2}{*}{$x^{\alpha \gamma}$, wt. $\%$} & \multirow[t]{2}{*}{$x^{\gamma \alpha}$, wt. $\%$} & \multirow[t]{2}{*}{$\alpha_{3}, \mathrm{~m} \mathrm{~s}^{-1 / 2}$} \\
\hline$P A G S=11 \mu \mathrm{m}$ & $P A G S=76 \mu \mathrm{m}$ & & & & \\
\hline $10.9 \times 10^{3}$ & $75.8 \times 10^{3}$ & $1.20 \times 10^{-13}$ & 0.016 & 0.903 & $6.01 \times 10^{-7}$ \\
\hline
\end{tabular}

Table IV. $S_{V}^{I N C}, \boldsymbol{D}, \mathbf{x}^{\alpha \gamma}, \boldsymbol{x}^{\gamma \alpha}$ and $\alpha_{3}$ values for a temperature of $913 \mathrm{~K}$ 
Figure 7 shows the evolution of the volume fraction of idiomorphic ferrite, $\xi$, formed during the isothermal decomposition of austenite at $913 \mathrm{~K}$ for two very different PAGS. Figure 8 represents a comparison between the experimental and calculated values of $\xi . R^{2}$ in this figure is the square correlation factor of the experimental and calculated volume fraction of idiomorphic ferrite. This parameter quantifies the accuracy of the model. Points lying on the line of unit slope show a perfect agreement between experimental and calculated values. From these figures it is concluded that a good agreement between experiment and theory exists. The accuracy of the model is higher than 90\%, which can be considered excellent for kinetic models.

Additionally, results in Fig. 7 show a strong influence of the PAGS on the idiomorphic ferrite formation. As above mentioned, this influence is a consequence of the competition process between grain boundary and intragranular nucleation. As PAGS increases, the number of intragranular nucleation sites increases to the detriment of the number of grain boundary nucleation sites. Consequently, the volume fraction of idiomorphic ferrite increases, as it is shown in micrographs in Fig. 9.

\section{CONCLUSIONS}

1. A kinetic model has been proposed for the isothermal formation of idiomorphic ferrite. The consideration of a parabolic law for the growth of idiomorphic ferrite is the most suitable representation of the idiomorphic ferrite formation kinetics. Experimental validation of this model has been carried out using dilatometric and metallographic analysis. An excellent agreement (accuracy higher than 90\% in square correlation factor) has been found between 
the experimental and calculated volume fraction of idiomorphic ferrite isothermal formed at $913 \mathrm{~K}$ in a $0.37 \mathrm{C}-1.45 \mathrm{Mn}-0.11 \mathrm{~V}$ (in wt-\%) microalloyed steel with two very different PAGSs.

2. In this steel, idiomorphic ferrite nucleates intragranularly on ellipsoidal manganese sulfide inclusions homogeneously distributed inside the austenite grains. Since the excellent agreement between experimental and calculated results, it is concluded that, the equation reported by Kluken and Grong, which convert the analytical oxygen and sulfur concentration into an equivalent inclusion volume, is a sensible expression for calculation of the volume fraction of inclusions in the steel.

3. An expression to determine the density of intragranular nucleation sites as a function of the PAGS, dimensions and volume fraction of inclusion has been proposed. Since allotriomorphic and idiomorphic ferrite transformations are competitive processes, idiomorphic ferrite is formed instead of allotriomorphic ferrite as the density of intragranular nucleation sites is in the order of that of grain boundary nucleation sites. Thus, as PAGS increases, idiomorphic ferrite formation is promoted. 


\section{ACKNOWLEDGEMENTS}

The authors acknowledge financial support from the Spanish Comisión Interministerial de

Ciencia y Tecnología (CICYT) (project-PETRI 95-0089-OP). GSB Acero S.A and CEIT are thanked for providing the steel and their collaboration in this project. 


\section{REFERENCES}

1. F. Ishikawa, T. Takahashi, and T. Ochi: Metall. Mater. Trans., 1994, vol. 25A, pp. 929-936.

2. D.J. Abson and R.J. Pargerter: Int. Met., Rev., 1986, vol. 31, pp. 141-194.

3. R.A. Farrar and P.L. Harrison: J. Mater. Sci., 1987, vol. 22, pp. 3812-3820.

4. Z. Zhang and R.A. Farrar: Mater. Sci. Technol., 1996, vol. 12, pp. 237-260.

5. I. Madariaga, and I. Gutiérrez, in Proc. of the Congreso Nacional de Tratamientos Térmicos y de Superficie TRATERMAT 98, M. Carsí et al., CENIM - CSIC, Madrid, Spain, 1998, pp. 143-151.

6. C. García de Andrés, C. Capdevila, and F. G. Caballero, in Proc. of the International Conference on Materials in Oceanic Environment EUROMAT 98, L. Faria, SPM - FEMS, Lisbon, Portugal, 1998, pp. 217-221.

7. I. Madariaga, and I. Gutiérrez: Acta Mater., 1997, vol. 37, pp. 1185-1192.

8. I. Madariaga, I. Gutiérrez, C. García de Andrés, and C. Capdevila: Scripta Mater.: 1999, vol. 41, pp. 229-235.

9. K. Yamamoto, S. Matsuda, T. Haze, R. Chijiiwa, and H. Mimura, in Proc. Symp. On Residual and Unspecified Elements in Steel, ASTM, Philadelphia, PA, 1989, pp. 1-24.

10. T. Ochi, T. Takahashi, and H. Harada: Iron Steelmaker, 1989, vol. 16, pp. 21-29.

11. H.K.D.H. Bhadeshia: Progress Material Science, 1985, vol. 29, pp. 321-386.

12. C. Garcia de Andres, C. Capdevila, F.G. Caballero, and H.K.D.H. Bhadeshia: Scripta Materialia, 1998, vol. 39, pp. 853-856.

13. C. Garcia de Andres, F.G. Caballero, C. Capdevila, and H.K.D.H. Bhadeshia: Scripta Materialia, 1998, vol. 39, pp. 791-796.

14. F.G. Caballero, C. Capdevila, and C. Garcia de Andres: Scripta Materialia, 2000, vol. 42, pp. 1159-1165. 
15. H.K.D.H. Bhadeshia, Bainite in Steels, The institute of Materials, London, UK, 1992, p. 245.

16. C. García de Andrés, G. Caruana, and L.F. Alvarez: Mater. Sci. Eng., 1998, vol. A241, pp. 211-215.

17. Vander Voort GF, Metallography. Principles and Practice, McGraw-Hill Book Company, NY, 1984. p. 427.

18. A.O. Kluken and O. Grong: Metall. Mater. Trans., 1989, vol. 20A, pp. 1335-1349.

19. S.M. Hodson, MTDATA-Metallurgical and Thermomechanical Databank, National Physical Laboratory, Teddington, UK, 1989, p. 1.

20. H.I. Aaronson, in The Decomposition of Austenite by Diffusional Processes, V.F. Zackay and H.I. Aaronson, Interscience Publishers, New York, 1962, pp. 387-546.

21. C.A. Dube, H. I. Aaronson ,and R. F. Mehl: Revue de Metallurgie, 1958, vol. 3, pp. 201-213.

22. O. Grong, Metallurgical Modelling of Welding, Institute of Materials, H.K.D.H. Bhadeshia, London, UK, 1997, p. 415.

23. J.W. Christian, Theory of transformations in Metals and Alloys, $2^{\text {nd }}$ edition, Part I, Pergamon Press, Oxford, UK, 1975, p.476.

24. S.J. Jones and H.K.D.H. Bhadeshia: Metall. Mater. Trans., 1997, vol. 28A, pp. 2005-2013.

25. M. Avrami: J. Chem. Phys., 1939, 7, p. 1103-1118.

26. W.F. Lange, M. Enomoto, and H.I. Aaronson: Metall. Mater. Trans., 1988, vol. 19A, pp. 427-440.

27. R.C. Reed and H.K.D.H. Bhadeshia: Mater. Sci. Technol., 1992, vol. 8, pp. 421-435.

28. G.J. Shiflet, J.R. Bradley, and H.I. Aaronson: Metall. Mater. Trans., 1978, vol. 9A, pp. 9991008.

29. H.K.D.H. Bhadeshia: Metal Sci., 1981, vol. 15, pp. 477-479. 

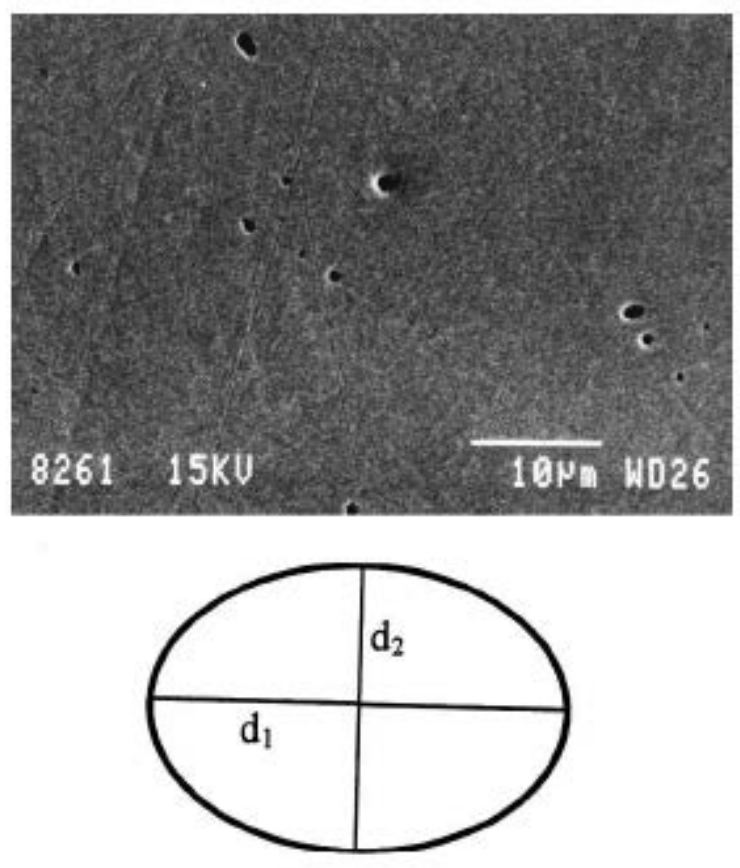

(a)
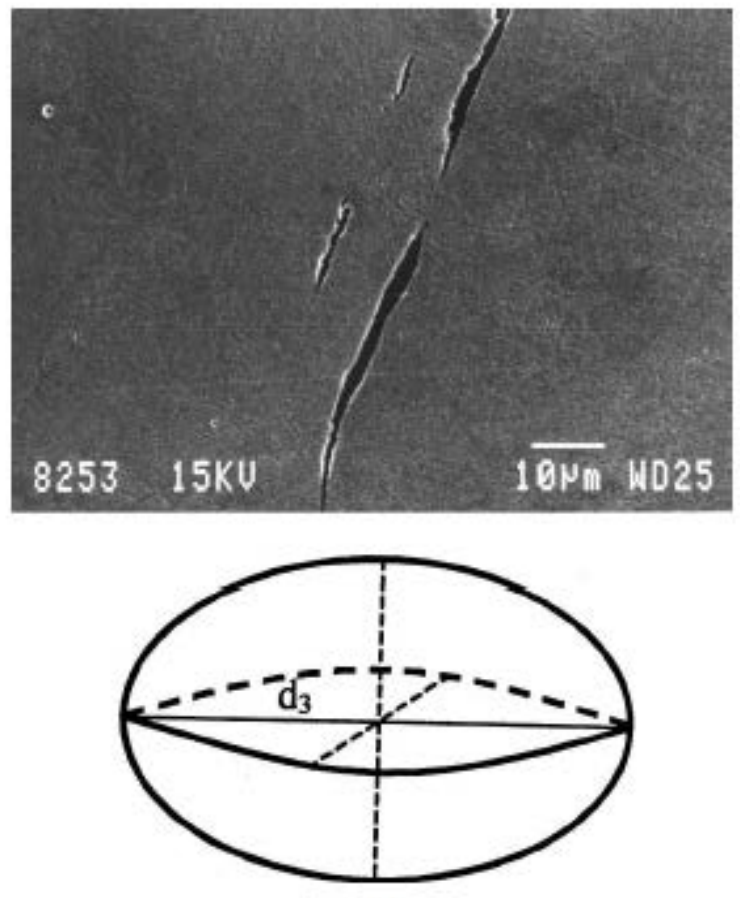

(b)

Fig. 1- Morphology of inclusions; (a) transversal and (b) longitudinal section to rolling direction. 


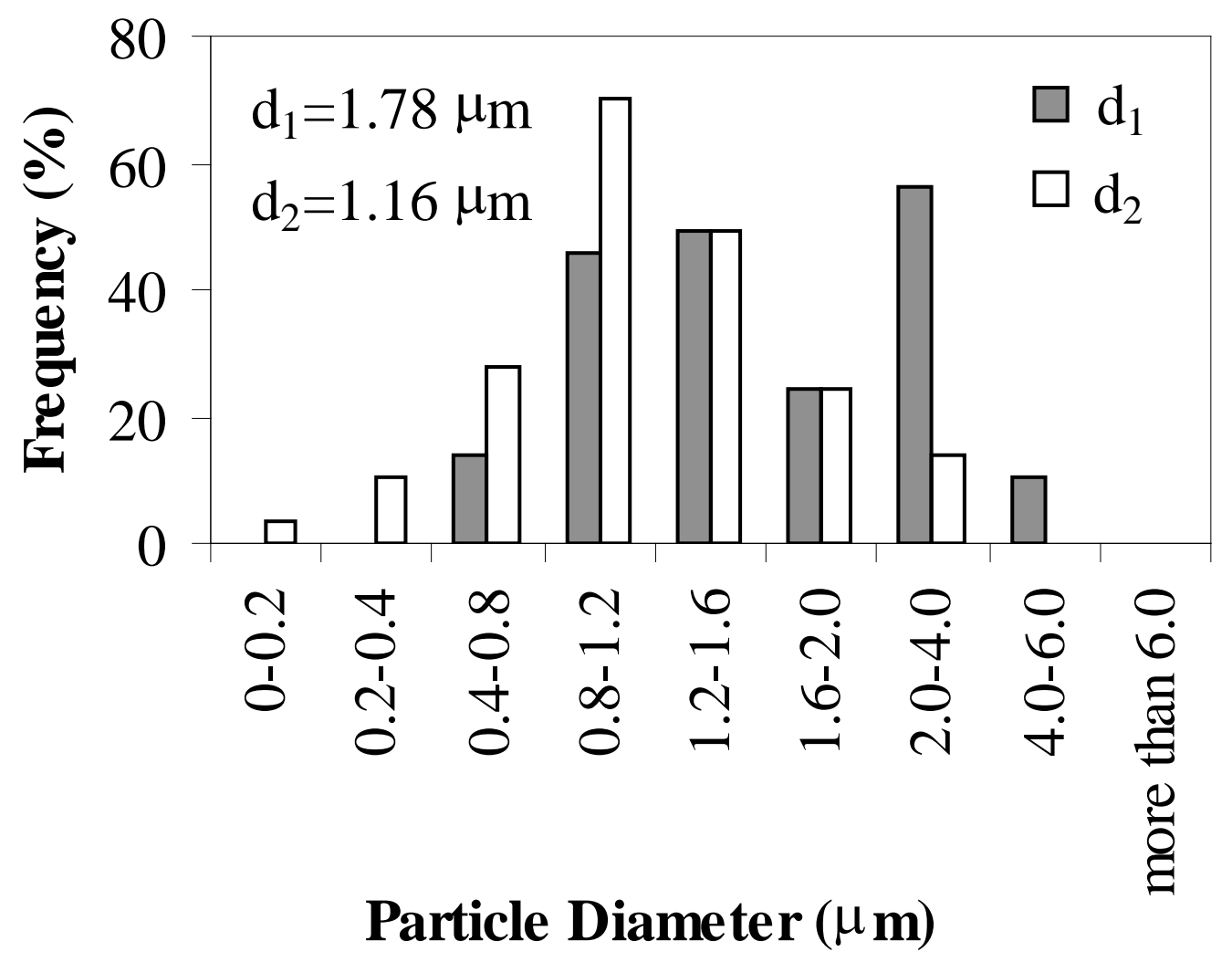

(a)

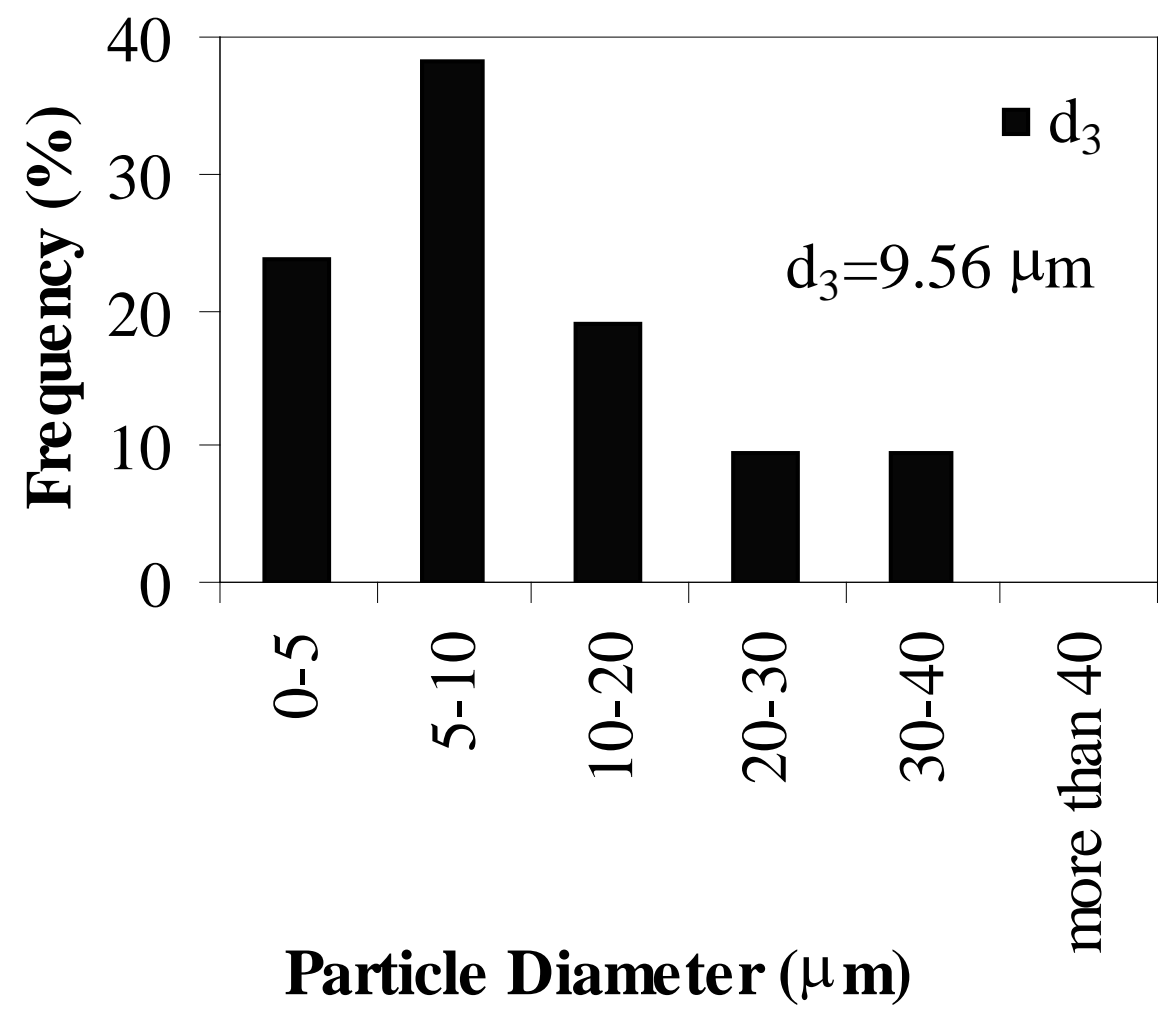

(b)

Fig. 2- Size distribution of inclusion; (a) transversal and (b) longitudinal section to rolling direction. 

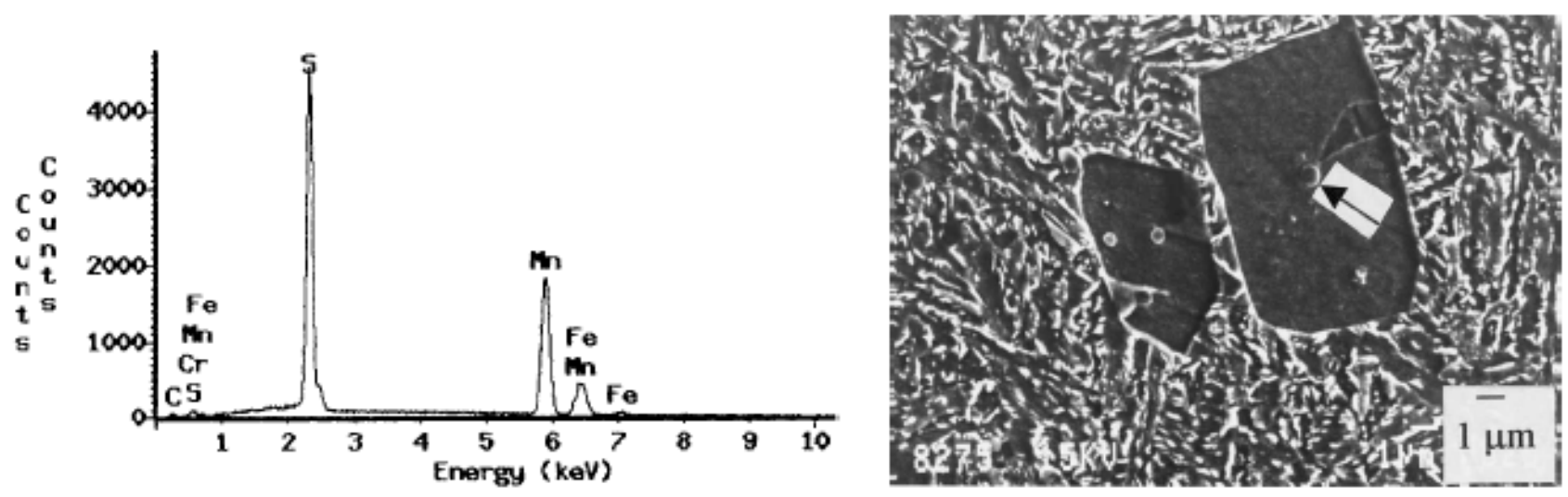

Fig. 3 - EDX spectrum of an inclusion (see arrow) where idiomorphic ferrite nucleates. 


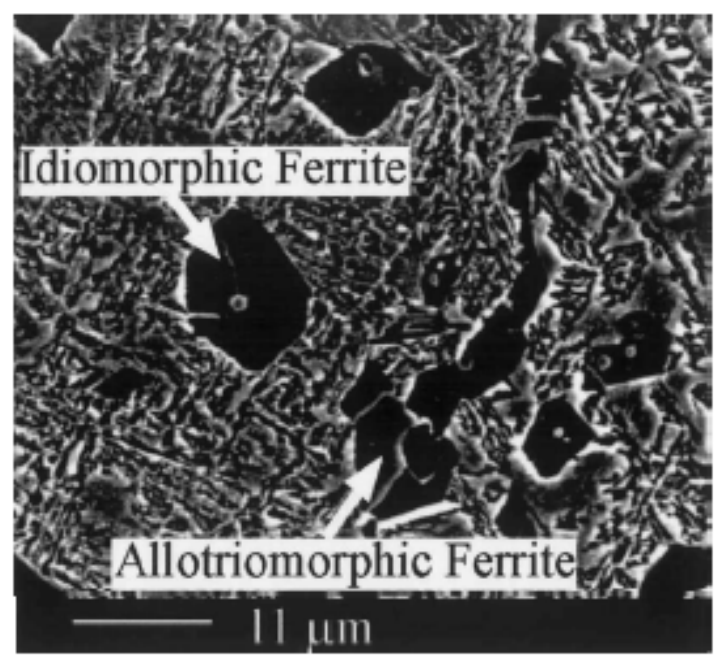

Fig. 4 - SEM micrograph of idiomorphic and allotriomorphic ferrite 


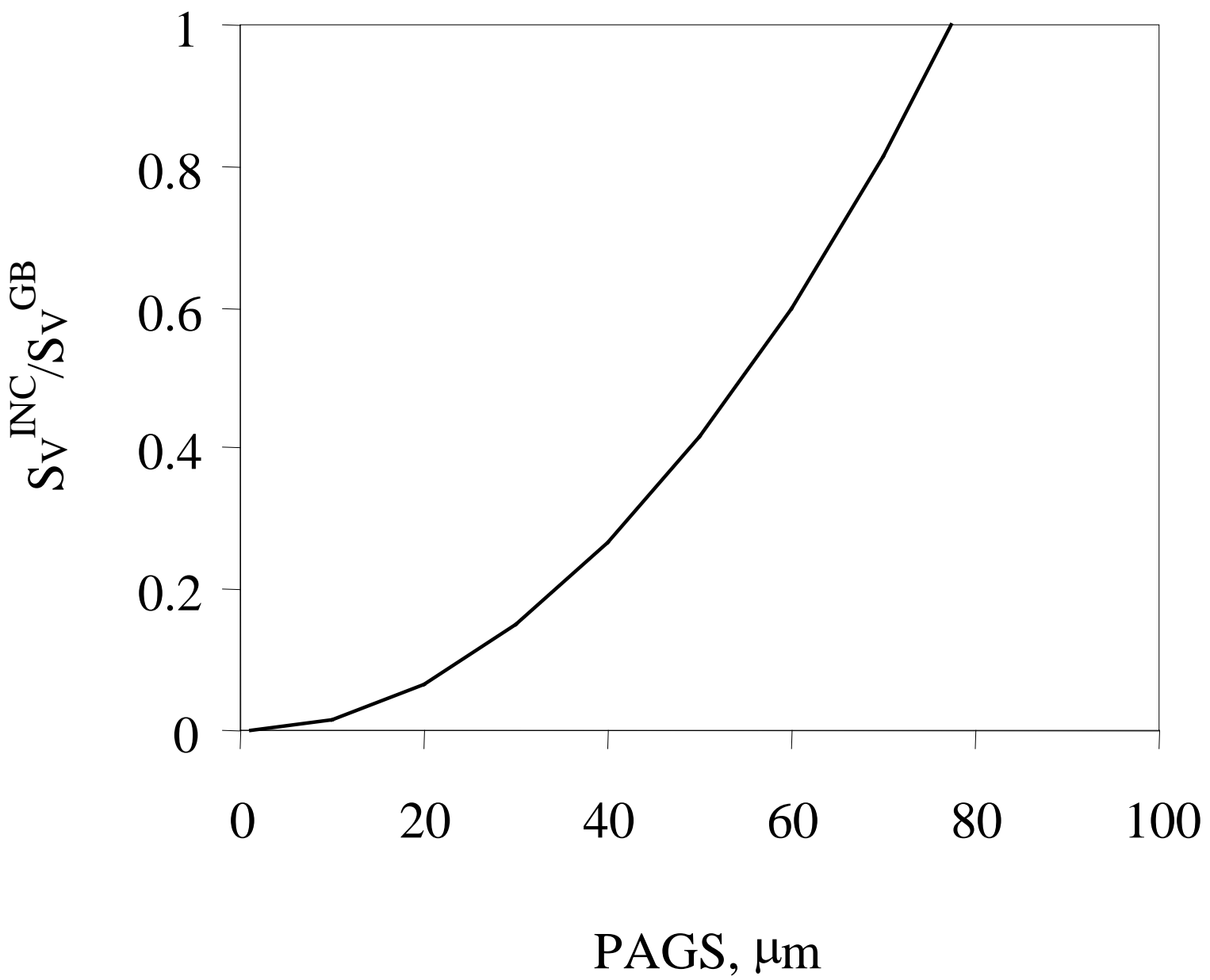

Fig. 5 - Ratio between intragranular and grain boundary nucleation of ferrite as a function of the PAGS. 


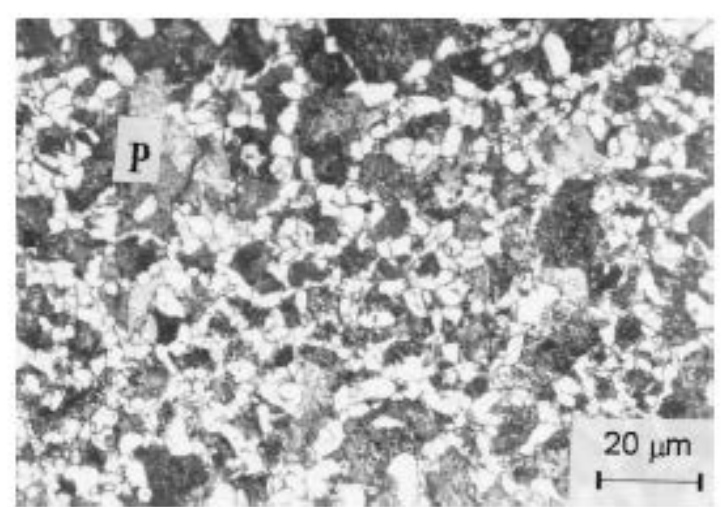

(a)

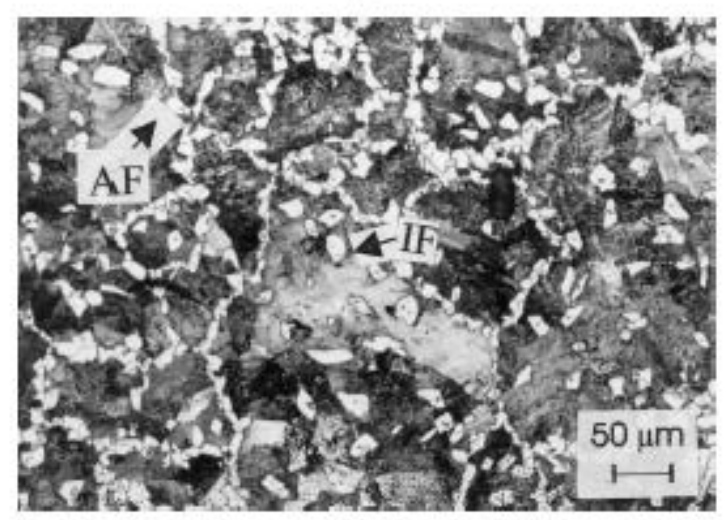

(b)

Fig. 6 - Microstructures obtained after isothermal heat treatment at $913 \mathrm{~K}$ during $1 \mathrm{~h}$ for a PAGS of

(a) $11 \mu \mathrm{m}$ and (b) $76 \mu \mathrm{m}$. (IF is idiomorphic ferrite; AF is allotriomorphic ferrite and $\mathrm{P}$ is pearlite) 


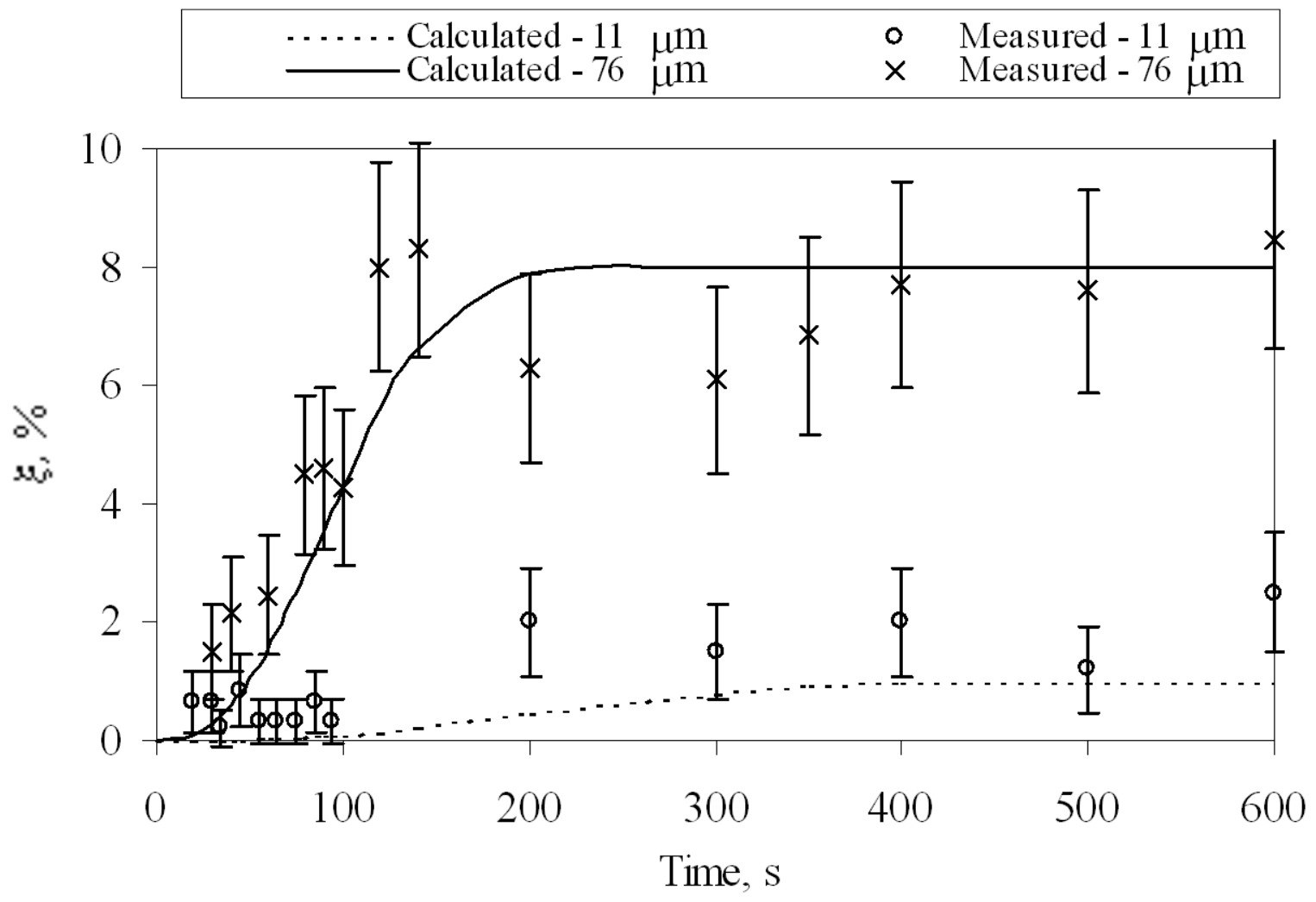

Fig. 7 - Evolution of the volume fraction of idiomorphic ferrite, $\xi$, during the isothermal decomposition of austenite at $913 \mathrm{~K}$, for two different PAGS. 


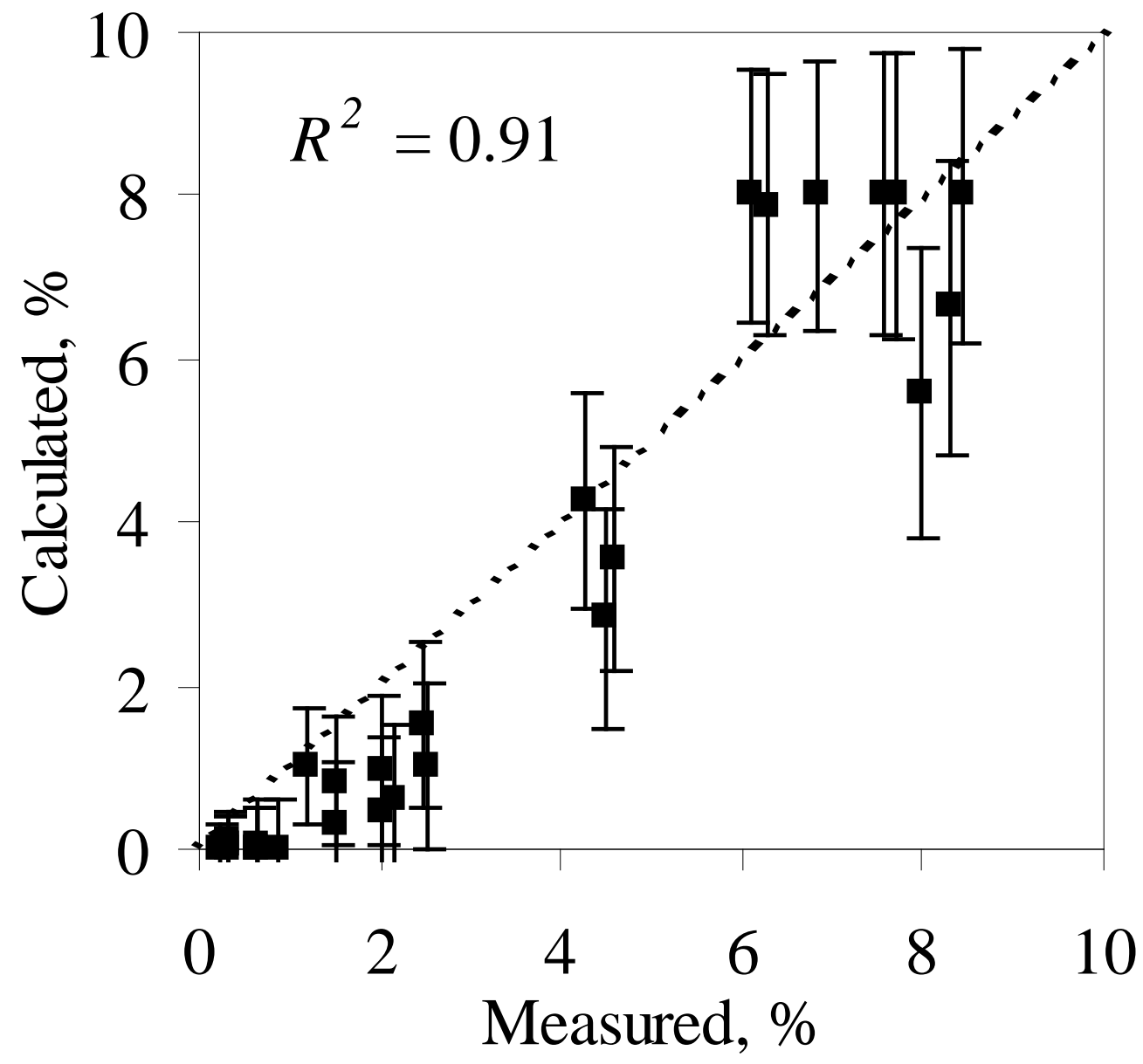

Fig. 8 - A comparison of the experimental and calculated values of volume fraction of idiomorphic ferrite. 


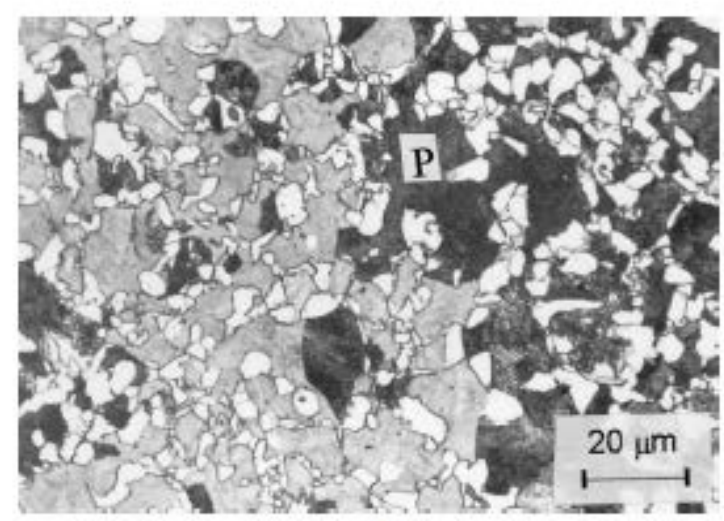

(a)

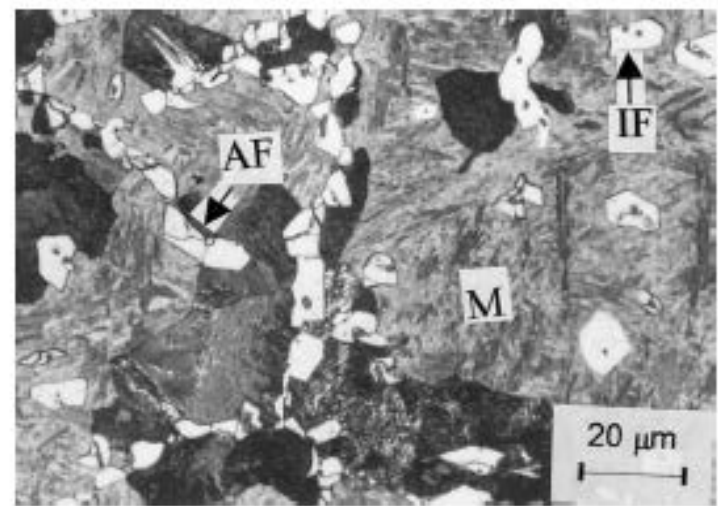

(b)

Fig. 9 - Microstructures obtained after isothermal heat treatment at $913 \mathrm{~K}$ during $80 \mathrm{~s}$ for a PAGS of;

(a) $11 \mu \mathrm{m}$ and (b) $76 \mu \mathrm{m}$. (IF is idiomorphic ferrite; AF is allotriomorphic ferrite; $\mathrm{P}$ is pearlite and $\mathrm{M}$ is martensite) 